\title{
Antigenic and genomic relation between human influenza $A$ (H3N2) viruses circulating in Argentina during 1998 and the H3N2 vaccine component
}

\author{
Andrea V. Pontoriero, ${ }^{1}$ Elsa G. Baumeister, ${ }^{1}$ Ana M. Campos, ${ }^{1}$ \\ Vilma L. Savy, ${ }^{1}$ Yi P. Lin, ${ }^{2}$ and Alan J. Hay ${ }^{2}$
}

ABSTRACT Objective. Due to the lack of correlation from 1994 to 1997 between the A H3N2 component of the influenza vaccine recommended for this period and the circulating viruses in Argentina, we decided to study the antigenic and genomic relationships of the 1998 A H3N2 Argentine circulating strains with the corresponding vaccine component for that year as recommended by the World Health Organization (WHO).

Methods. We selected 18 influenza A H3N2 strains isolated in Argentina during 1998 to carry out an antigenic and genomic study of their hemagglutinin (HA) and neuraminidase (NA) proteins. For the genomic study we added 3 isolates from Uruguay. We compared the Argentine and Uruguayan strains with available reference strains.

Results. We found that all 18 strains from Argentina were similar to the A/Sydney/5/97 (H3N2) strain, as opposed to the A/Wuhan/359/95 (H3N2) strain, which was the vaccine component. This result was confirmed by the genomic study.

Conclusions. The approach that we applied in Argentina has improved the quality and quantity of information about influenza in the country. This type of work should be encouraged in other countries in order to help choose the most appropriate vaccine components each year and provide individuals with the best possible protection against influenza.

Key words Influenza, immunization, Argentina.

Influenza viruses are unique in their ability to cause annual epidemics and

\footnotetext{
1 Instituto Nacional de Enfermedades InfecciosasAdministración Nacional de Laboratorios e Institutos de Salud "Doctor Carlos G. Malbrán," Departamento Virología, Servicio Virosis Respiratorias, Buenos Aires, Argentina. Send correspondence to: Andrea V. Pontoriero, Servicio Virosis Respiratorias, Departamento Virología, INEI-ANLIS “Carlos G. Malbrán," Av. Vélez Sarsfield 563 (1281), Buenos Aires, Argentina; telephone/ fax: 5411 4301-1035; email:vrmalbra@datamarkets.com.ar

2 National Institute for Medical Research, Virology Division, The Ridgeway, Mill Hill, London, England, United Kingdom.
}

periodic pandemics, both of which spread rapidly and may affect all or most age groups (1). In epidemics $10 \%-20 \%$ of the general population may be affected, and in most years there is measurable excess mortality due to influenza (2).

The annual influenza epidemics are caused by the rapid evolution of the viral genome. Such changes can be monitored through antigenic analysis and the study of gene sequencing, particularly the gene that codes for viral hemagglutinin (HA) (3). The HA, a surface glycoprotein of the viral envelope, is the major target for neutralizing antibodies. Point mutations in the potential domains of this protein are thought to allow the virus to evade the human immune response (4).

Some influenza seasons are more severe than others, and this is thought to reflect the degree of HA protein change between earlier antigenic variants and new ones (5). In 1947 an international network was created 
for the surveillance of influenza viruses, with the objective of studying influenza epidemiology and the origins of epidemic and pandemic viruses (6). Now operated by the World Health Organization (WHO), this global influenza network consists of four international collaborating reference centers (located in Atlanta, United States of America; London, United Kingdom; Melbourne, Australia; and Tokyo, Japan) and 110 national reference centers around the world. The international reference centers are in charge of analyzing the information collected by the national reference centers and utilizing that information to select the influenza vaccine formula to be implemented in each season.

In 1995 a national laboratory network was created in Argentina to carry out the surveillance of respiratory viruses, including influenza, by means of viral diagnosis of clinical samples. There are now 22 laboratories participating intensively in this network.

Before 1998, all the information that the international network generated was analyzed in one annual meeting where decisions were made as to which strains were going to be included in the vaccine formula in order to have the highest possible level of prevention. In spite of these efforts, from 1994 to 1997 in Argentina we found a lack of correlation between the H3N2 component of the vaccine and the circulating viruses in the country (7).

Since 1998 the WHO has held a second annual meeting each September to consider the information gathered in the Southern Hemisphere and decide if there is a need to reformulate the vaccine to be used by these countries.

The aim of this work was to study the influenza A H3N2 strains that circulated in Argentina in 1998 and to analyze the relationship that existed between them and the H3N2 component of the vaccine that the WHO had recommended for that same period. The 1998 vaccine formula included the following strains: an A/Wuhan/359/95 (H3N2)-like virus, an A/Bayern/7/95 (H1N1)-like virus, and a B/Beijing/ 184/93-like virus (8).
We performed the antigenic and genomic studies of the influenza A viruses using clinical isolates collected in 1998 from six Argentine provinces. We compared those Argentine isolates with other contemporary isolates and with reference strains by constructing sequence alignments and phylogenetic trees

\section{MATERIALS AND METHODS}

\section{Clinical samples and viral strains}

We collected 602 samples of throat swabs, nasopharyngeal swabs, tracheal aspirates, and bronchoalveolar lavages that had come from pediatric and adult outpatients and inpatients with a positive laboratory diagnosis of the influenza A virus. This influenza diagnosis was performed by the National Reference Center for Influenza Surveillance of the National Infectious Diseases Institute and by the hospital laboratories in the national network. From these 602 samples 210 viruses were isolated in Madin-Darby canine kidney (MDCK) cell cultures at the National Reference Center. The presence of virus was confirmed by means of direct immunofluorescence and hemagglutination techniques performed no later than 7 days postinfection (9)

From these 210 isolates we selected 18 strains that had been collected between May and August of 1998 in six Argentine provinces: 1 strain from Salta, 2 from Tucumán, 2 from Neuquén, 3 from Buenos Aires, 4 from Córdoba, and 6 from Tierra del Fuego.

\section{Viral diagnosis}

The detection of viral antigens corresponding to influenza A and B in the Argentine clinical samples was performed by the indirect immunofluorescence (IIF) technique at the National Reference Center and the laboratory network. Type-specific monoclonal antibodies directed against the viral nucleoprotein (provided by the Centers for Disease Control and Prevention of Atlanta, Georgia, United States of Amer- ica) and an anti-mouse-fluorescein conjugate (DAKO A/S, Glostrup, Denmark) were used.

\section{Antigenic study}

The subtyping and the antigenic characteristics of the 18 Argentine isolates were determined in two steps. First, the strains were subtyped in $\mathrm{H} 3$ and $\mathrm{H} 1$ by the hemagglutination inhibition (HI) technique, using postinfection sheep antiserum (10) with a WHO kit provided by the WHO influenza collaborating center at the United States Centers for Disease Control and Prevention (CDC), in Atlanta, Georgia. This kit included antigens and subtype-specific antisera for subtyping influenza viruses by HI. Second, we carried out HI with a panel of postinfection ferret antisera generated against 6 influenza A (H3N2) reference viruses: A/Wuhan/359/95, A/ Nanchang/933/95, A/Sydney/5/97, A/Johannesburg/29/98, A/Victoria/ 318/98, and A/Finland/620/99. After incubating the antigens with the different antisera, a suspension of turkey red blood cells $0.5 \%$ was used to reveal the result. The first step was performed at the National Reference Center in Argentina and the second one was done in London at the international reference center, which is commonly known as "WIC." The HI results obtained for these Argentine isolates were also confirmed and completed by the CDC. The criterion we used to interpret the results was the following: an isolate that reacted with a reference antiserum at a titer equal to that at which it reacted with the reference homologous virus $( \pm$ one twofold dilution) was considered to closely resemble that virus (10).

\section{Nucleotide sequencing}

Three influenza A strains from the city of Montevideo, Uruguay, obtained in July 1998, were added to the study of the 18 Argentine isolates. We considered that the analysis of these Uruguayan strains was of great impor- 
tance since they were isolated in the same hemisphere and in the same time period as the Argentine ones.

The viral RNA extraction from the Argentine and Uruguayan cell culture supernatants with HA titers $\geq 16$ using proteinase $\mathrm{K}$, phenol-chloroform (1:1), and precipitation with $70 \%$ ethanol was carried out at WIC. This viral RNA was used to amplify the HA and neuraminidase (NA) genes by reverse transcriptase polymerase chain reaction (RT-PCR). In each case we used two pairs of primers, allowing the synthesis of the full length of both proteins, which were 1650 and $1410 \mathrm{nu}-$ cleotides, respectively. The sequencing of the amplified segments was done using the PRISM Ready Reaction Dye Deoxy Terminator Cycle Sequencing kit with an ABI Model 373A DNA Se- quencer (Perkin-Elmer, Applied Biosystems Division, Foster City, California, United States).

\section{Phylogenetic analysis}

Sequence data were edited and analyzed in London at WIC using the Wisconsin Sequence Analysis Package, version 8 (11). At the National Reference Center in Argentina we calculated sequence distances from the alignments using the DNADIST program for phylogenetic analysis (12). We used the NEIGHBOR and TREEVIEW programs (13) to cluster the distance data and to produce the trees. We evaluated the robustness of the trees by bootstrap analysis (100 trees) (14) using the SEQBOOT and CON-
SENCE programs. The DNADIST, SEQBOOT, CONSENCE, and NEIGHBOR programs are all part of the PHYLIP computer software package, version 3.57 (12).

\section{RESULTS}

\section{Antigenic study}

The first part of our antigenic study showed that the 18 Argentine isolates studied belonged to the subtype H3. Based on these results, these strains were compared with 6 influenza A H3N2 strains. In this stage, we tested 17 of the 18 Argentine strains; Table 1 shows the results. Out of those 17 strains tested, 16 of them were similar

TABLE 1. Results of the hemagglutination inhibition $(\mathrm{HI})$ test comparing the $\mathrm{HI}$ titers obtained for the Argentine isolates with the ones obtained for the incluenza A H3N2 reference strains against their 6 homologous ferret antisera, Argentina, 1998

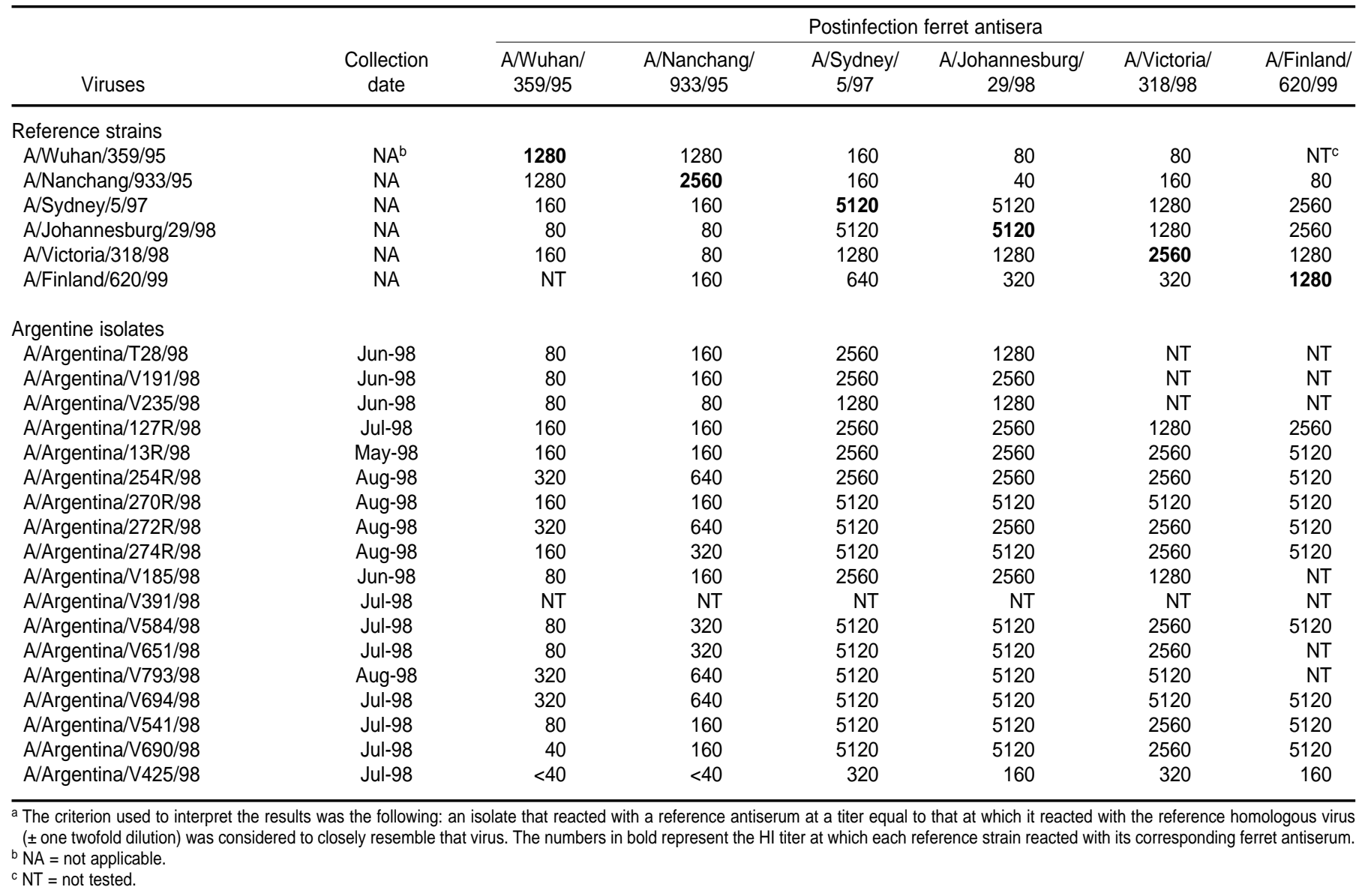


to the A/Sydney/5/97 strain, as indicated by the HI titers obtained using the A/Sydney/5/97 ferret antiserum in comparison with the HI titers obtained with the A/Wuhan/359/95 antiserum. The ferret antiserum generated against the A/Wuhan/359/95 strain H3N2 component of the 1998 vaccine formula scarcely recognized the A/Sydney/5/97 strain, with a HI titer of 160, versus its homologous strain, which had a HI titer of 1280 . When comparing some Argentine strains with the A/Finland/620/99 antiserum, we found that they crossed with this strain with titers similar to the ones observed with the Sydney strain. One of the Argentine strains, the A/Argentina/V425/98 one, which was from Tucumán, showed low reactivity with all the ferret antisera tested.

\section{Genomic study}

The genomic study of the Uruguayan and Argentine strains was performed in a similar way at WIC; the antigenic analysis of the Uruguayan strains had been previously done at that institution.

HA study. The alignment based on the HA1 portion of the HA of both the Argentine and Uruguayan strains carried out at WIC showed that the number of point nucleotide changes was higher than with the HA2 portion (data not shown). We expected this result since the HA1 is the more variable portion of the HA due to the fact that it is where the antigenic sites are located (15). There are hypervariable regions in the HA1 portion of the HA recognized by the neutralizing antibodies generated by the host immunological response.

In the alignment generated based on the HA1 portion amino acid sequences, it was observed that the Argentine and Uruguayan strains presented changes that were repeated among themselves and that appeared in the A/Sydney/5/97 reference strain. This can be seen in Table 2, as shown by the amino acid changes that are present in the Argentine and Uruguayan strains. The

TABLE 2. Amino acid changes in the HA1 portion of the hemagglutinin (HA) protein observed in influenza $A(H 3 N 2)$ reference strains and in selected circulating influenza $A(H 3 N 2)$ viruses in Argentina and Uruguay, 1998

\begin{tabular}{lllllllll}
\hline & \multicolumn{6}{c}{ Amino acid position in the HA1 portion of the HA } \\
\cline { 2 - 7 } \multicolumn{1}{c}{ Strain } & 62 & 144 & 145 & 156 & 158 & 196 & 276 \\
\hline Reference strains & & & & & & & \\
A/Johannesburg/33/94 & $\mathrm{K}$ & $\mathrm{V}$ & $\mathrm{N}$ & $\mathrm{K}$ & $\mathrm{E}$ & $\mathrm{V}$ & $\mathrm{N}$ \\
A/Wuhan/359/95 & $\mathrm{K}$ & $\mathrm{V}$ & $\mathrm{K}$ & $\mathrm{K}$ & $\mathrm{E}$ & $\mathrm{V}$ & $\mathrm{N}$ \\
A/South Africa/1147/96 & $\mathrm{K}$ & $\mathrm{V}$ & $\mathrm{K}$ & $\mathrm{K}$ & $\mathrm{E}$ & $\mathrm{V}$ & $\mathrm{N}$ \\
A/Sydney/5/97 & $\mathrm{E}$ & $\mathrm{I}$ & $\mathrm{K}$ & $\mathrm{Q}$ & $\mathrm{K}$ & $\mathrm{A}$ & $\mathrm{K}$ \\
Argentine and Uruguayan strains & & & & & & & \\
A/Montevideo/2728/98 & $\mathrm{E}$ & $\mathrm{I}$ & $\mathrm{K}$ & $\mathrm{Q}$ & $\mathrm{K}$ & $\mathrm{A}$ & $\mathrm{K}$ \\
A/Argentina/V541/98 & $\mathrm{E}$ & $\mathrm{I}$ & $\mathrm{K}$ & $\mathrm{Q}$ & $\mathrm{K}$ & $\mathrm{A}$ & $\mathrm{K}$ \\
A/Argentina/V793/98 & $\mathrm{E}$ & $\mathrm{I}$ & $\mathrm{K}$ & $\mathrm{Q}$ & $\mathrm{K}$ & $\mathrm{A}$ & $\mathrm{K}$ \\
A/Argentina/254R/98 & $\mathrm{E}$ & $\mathrm{I}$ & $\mathrm{K}$ & $\mathrm{Q}$ & $\mathrm{K}$ & $\mathrm{A}$ & $\mathrm{K}$ \\
A/Argentina/V425/98 & $\mathrm{E}$ & $\mathrm{I}$ & $\mathrm{K}$ & $\mathrm{Q}$ & $\mathrm{K}$ & $\mathrm{A}$ & $\mathrm{K}$ \\
A/Argentina/13R/98 & $\mathrm{E}$ & $\mathrm{I}$ & $\mathrm{K}$ & $\mathrm{Q}$ & $\mathrm{K}$ & $\mathrm{A}$ & $\mathrm{K}$ \\
A/Argentina/V391/98 & $\mathrm{E}$ & $\mathrm{I}$ & $\mathrm{K}$ & $\mathrm{Q}$ & $\mathrm{K}$ & $\mathrm{A}$ & $\mathrm{K}$ \\
\hline
\end{tabular}

a The numbers indicate the amino acid positions in the HA1 portion of the HA molecule. The letters represent these amino acids: A, alanine; E, glutamic acid; I, isoleucine; K, lysine; N, asparagine; Q, glutamine; V, valine.

previous reference strains did not present the majority of these amino acid changes. The A/Argentina/V425/98 strain, which showed low reactivity to all the H3 antisera tested in the HI, appeared to be similar to other Argentine and Uruguayan strains in the phylogenetic tree (Figure 1).

The amino acid sequences of the HA1 portions of the A/Wuhan/359/95 and A/Sydney/5/97 showed that these two reference strains differ from each other by 11 amino acids, which represents $3.35 \%$ of the total HA1 amino acids. All the Argentine strains varied in 13-16 amino acids with respect to the Wuhan strain and 5-8 amino acids when compared to the Sydney strain.

NA study. When we performed the NA analysis, we found that all the Argentine and Uruguayan strains were similar to the Sydney reference one. The changes at the amino acid level that occurred in more than one of the recent Argentine and Uruguayan strains with respect to the Wuhan and Sydney reference strains were: P45L, V263I, P267Q, and G401D (Table 3). The rest of the amino acid changes observed in both the Argentine and Uruguayan strains were present in the
A/Sydney/5/97 strain but not in the A/Wuhan/359/95 strain. Together with the phylogenetic tree based on the NA nucleotide sequences, this alignment analysis showed two key things: 1) that all the Argentine strains were homogeneous among themselves, as were also the Uruguayan ones, and 2) that the Argentine strains were very similar to the Uruguayan strains. At the same time, the Argentine and the Uruguayan strains were similar to A/Sydney/5/97 strain (Figure 2).

\section{DISCUSSION}

Both our HI antigenic study and our $\mathrm{HA}$ and NA genomic analysis showed that all the Argentine and Uruguayan strains were similar to each other. Fitting with this finding was the closeness in the isolation dates of these strains as well as their geographic proximity. The influenza A H3N2 viruses that circulated in Argentina and Uruguay in 1998 were antigenically similar to a new variant represented by A/Sydney/5/97. Whereas the WHO recommended the A/ Wuhan/359/95 (H3N2) strain as the prototype vaccine strain for the 19971998 period in the Northern Hemi- 
FIGURE 1. Phylogenetic tree based on the HA nucleotide sequences of 7 A H3N2 reference influenza viruses (in all-capital letters) and of 21 Argentine and 3 Uruguayan A H3N2 influenza strains isolated in 1998

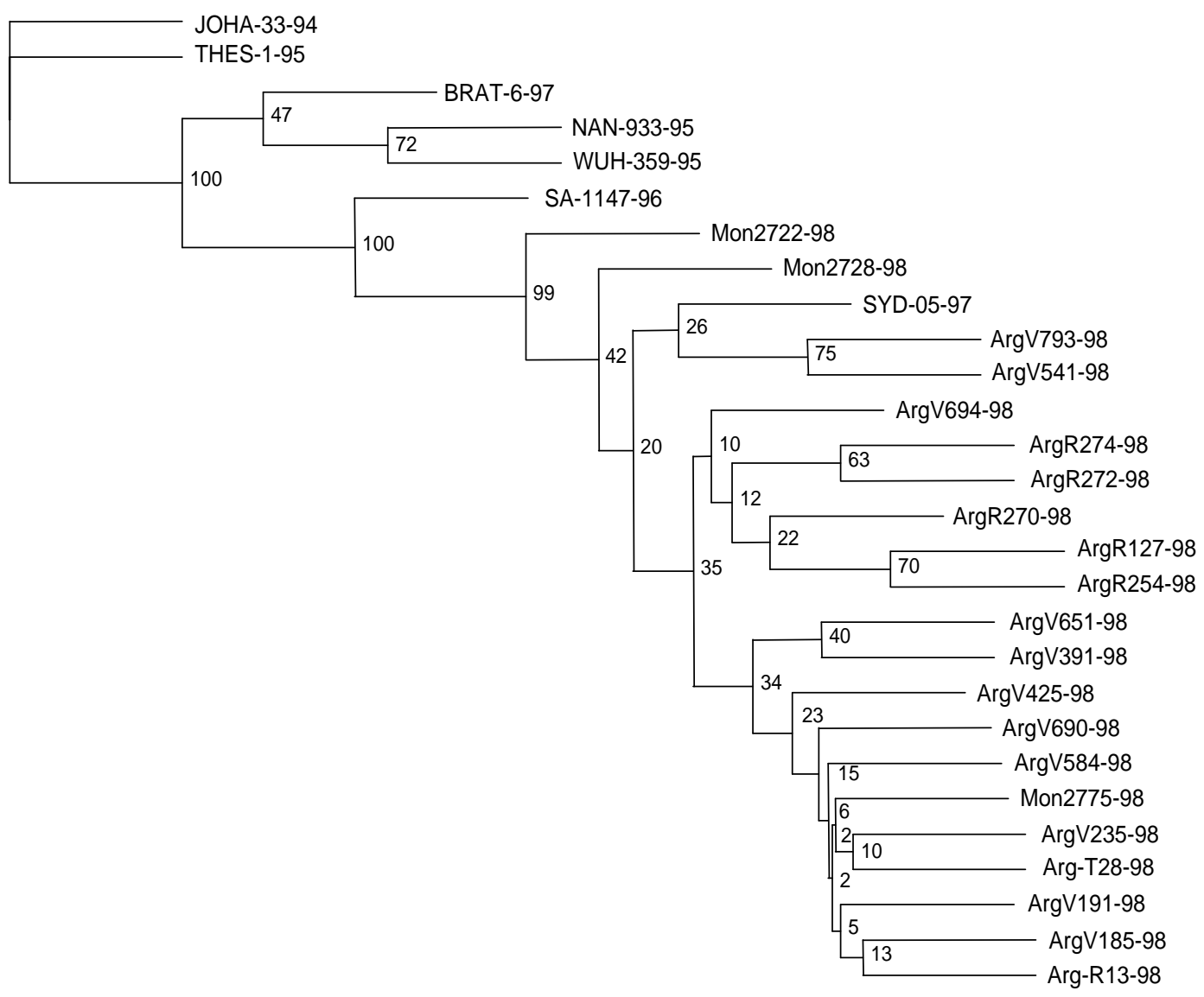

a This is a neighbor-joining analysis, as determined by the PHYLIP computer program (12). The horizontal spacing represents the number of nucleotide differences between branch points. Vertical lines are for spacing and labels. Numerical values represent bootstrapping confidence values. The figure includes the 18 Argentine and 3 Uruguayan influenza strains that we isolated as well as 3 other Argentine strains studied previously. The abbreviations and the respective full forms are: JOHA-33-94, A/Johannesburg/33/94; THES-1-95, A/Thessaloniki/1/95; BRAT-6-97, A/Bratislava/6/97; NAN-933-95, A/Nanchang/933/95; WUH-359-95, A/Wuhan/359/95; SA-1147-96, A/South Africa/1147/96; Mon2722-98, A/Montevideo/2722/98; Mon2728-98, A/Montevideo/ 2728/98; SYD-05-97, A/Sydney/5/97; ArgV793-98, A/Argentina/V793/98; ArgV541-98, A/Argentina/V541/98; ArgV694-98, A/Argentina/V694/98; ArgR274-98, A/Argentina/R274/98; ArgR27298, A/Argentina/R272/98; ArgR270-98, A/Argentina/R270/98; ArgR127-98, A/Argentina/R127/98; ArgR254-98, A/Argentina/R254/98; ArgV651-98, A/Argentina/V651/ 98; ArgV391-98, A/ Argentina/391/98; ArgV425-98, A/Argentina/V425/98; ArgV690-98, A/Argentina/V690/98; ArgV584-98, A/Argentina/V584/98; Mon2775-98, A/Montevideo/2775/98; ArgV235-98, A/Argentina/ V235/98; Arg-T28-98, A/Argentina/ T28/98; ArgV191-98, A/Argentina/V191/98; ArgV185-98, A/Argentina/V185/98; Arg-R13-98, A/Argentina/R13/98.

sphere and for the 1998 year in the Southern Hemisphere, the A/Sydney/ $5 / 97$ strain was only recommended for the following season. The A/ Sydney/5/97 strain had evolved from a variant represented by the $\mathrm{A} /$ South Africa/1147/96 strain. Although that A/South Africa/1147/96 strain was practically indistinguishable from the Wuhan one in the HI test, these two were clearly differentiated by the amino acid sequences that their respective HAs presented (16).

Our HI test also showed that the 1998 Argentine isolates were similar to strains that circulated in the Northern Hemisphere in the 1998-1999 period, represented by A/Finland/620/99. This coincides with what had been seen in previous years: the influenza strains from the Southern Hemisphere served as early markers of the expected strains in the Northern Hemisphere in the following period.

Regarding the viral HA, we detected some amino acid changes in the Argentine isolates with respect to the A/Sydney/5/97 reference strain in addition to the ones that appeared in Table 2 (data not shown). These changes were proline 103 to glutamine (P103Q) or tyrosine 137 to serine (Y137S), with the latter being more prevalent. This could be explained as the natural evolution of the influenza virus in the human population.

Four amino acid changes were observed at the NA level in our influenza A H3N2 isolates obtained during 1998. Some of these amino acid changes might antigenically affect the viral particle, particularly the one in the 401 position (16). This could be explained by the fact that seven chained segments in the NA, including the 400 
TABLE 3. Amino acid changes in the neuraminidase (NA) protein observed in influenza $A$ (H3N2) reference strains and in selected circulating influenza A (H3N2) viruses in Argentina and Uruguay, 1998

\begin{tabular}{llllllll}
\hline \multicolumn{1}{c}{ Strain } & \multicolumn{7}{c}{ Amino acid position in the NA } \\
\cline { 2 - 7 } & 45 & 127 & 263 & 267 & 370 & 381 & 401 \\
\hline Reference strains & & & & & & & \\
A/Johannesburg/33/94 & $\mathrm{P}$ & $\mathrm{G}$ & $\mathrm{V}$ & $\mathrm{P}$ & $\mathrm{L}$ & $\mathrm{G}$ & $\mathrm{G}$ \\
A/Wuhan/359/95 & $\mathrm{P}$ & $\mathrm{G}$ & $\mathrm{V}$ & $\mathrm{P}$ & $\mathrm{L}$ & $\mathrm{G}$ & $\mathrm{G}$ \\
A/South Africa/1147/96 & $\mathrm{P}$ & $\mathrm{D}$ & $\mathrm{V}$ & $\mathrm{P}$ & $\mathrm{L}$ & $\mathrm{E}$ & $\mathrm{G}$ \\
A/Sydney/5/97 & $\mathrm{P}$ & $\mathrm{D}$ & $\mathrm{V}$ & $\mathrm{P}$ & $\mathrm{F}$ & $\mathrm{E}$ & $\mathrm{G}$ \\
Argentine and Uruguayan strains & & $\mathrm{L}$ & $\mathrm{V}$ & $\mathrm{Q}$ & $\mathrm{F}$ & $\mathrm{E}$ & $\mathrm{D}$ \\
A/Montevideo/2728/98 & $\mathrm{L}$ & $\mathrm{D}$ & $\mathrm{I}$ & $\mathrm{Q}$ & $\mathrm{F}$ & $\mathrm{E}$ & $\mathrm{D}$ \\
A/Montevideo/2399/98 & $\mathrm{L}$ & $\mathrm{D}$ & $\mathrm{I}$ & $\mathrm{Q}$ & $\mathrm{F}$ & $\mathrm{E}$ & $\mathrm{D}$ \\
A/Argentina/V541/98 & $\mathrm{L}$ & $\mathrm{D}$ & $\mathrm{I}$ & $\mathrm{Q}$ & $\mathrm{F}$ & $\mathrm{E}$ & $\mathrm{D}$ \\
A/Argentina/V793/98 & $\mathrm{L}$ & $\mathrm{D}$ & $\mathrm{I}$ & $\mathrm{Q}$ & $\mathrm{F}$ & $\mathrm{E}$ & $\mathrm{D}$ \\
A/Argentina/13R/98 & $\mathrm{L}$ & $\mathrm{D}$ & $\mathrm{I}$ & $\mathrm{Q}$ & $\mathrm{F}$
\end{tabular}

a The numbers indicate the amino acid positions in the NA molecule. The letters represent these amino acids: D, aspartic acid; E, glutamic acid; $F$, phenylalanine; G, glycine; I, isoleucine; L, leucine; P, proline; Q, glutamine; V, valine.

FIGURE 2. Phylogenetic tree based on the NA nucleotide sequences of 4 A H3N2 reference influenza viruses (all-capital letters) and 18 Argentine and 3 Uruguayan A H3N2 influenza strains isolated in $1998^{a}$

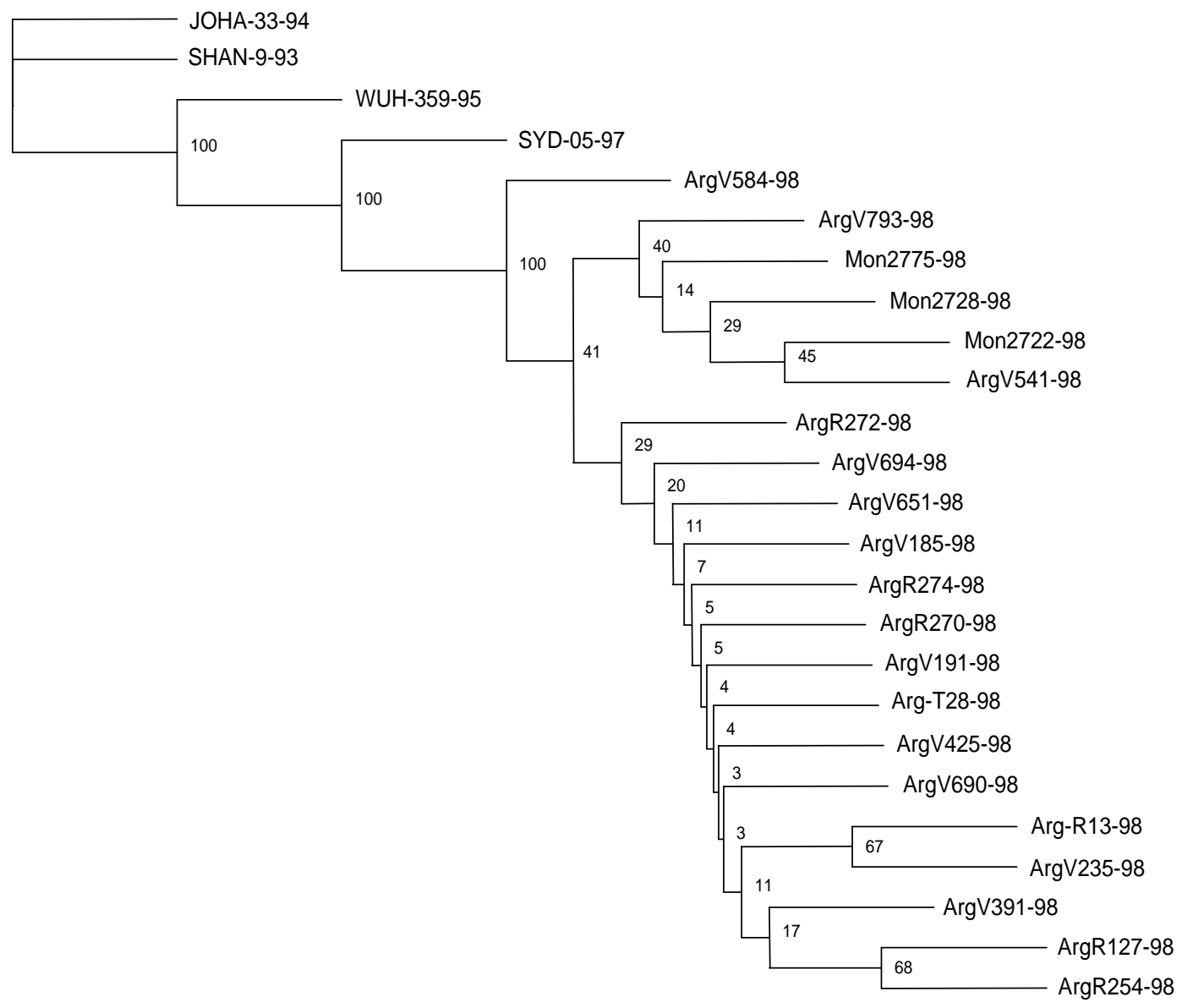

a This is a neighbor-joining analysis, as determined by the PHYLIP computer program (12). The horizontal spacing represents the number of nucleotide differences between branch points. Vertical lines are for spacing and labels. Numerical values represent bootstrapping confidence values. The abbreviations and the respective full forms are: JOHA-33-94, A/Johannesburg/ 33/94; SHAN-9-93, A/Shangdong/9/93; WUH-359-95, A/Wuhan/359/95; SYD-05-97, A/Sydney/5/97; ArgV584-98, A/Argentina/V584/98; ArgV793-98, A/Argentina/V793/98; Mon2775-98, A/Montevideo/2775/98; Mon2728-98, A/Montevideo/2728/98; Mon2722-98, A/Montevideo/2722/98; ArgV541-98, A/Argentina/V541/98; ArgR272-98, A/Argentina/R272/98; ArgV694-98, A/Argentina/ V694/98; ArgV651-98, A/Argentina/V651/98; ArgV185-98, A/Argentina/V185/98; ArgR274-98, A/Argentina/R274/98; ArgR270-98, A/Argentina/R270/98; ArgV191-98, A/Argentina/ V191/98; Arg-T28-98, A/Argentina/T28/98; ArgV425-98, A/Argentina/V425/98; ArgV690-98, A/Argentina/V690/98; Arg-R13-98, A/Argentina/R13/98; ArgV235-98, A/Argentina/ V235/98; ArgV391-98, A/Argentina/V391/98; ArgR127-98, A/Argentina/R127/98; ArgR254-98, A/Argentina/R254/98. 
403 portion, have been identified as potential contributors to interactions with antibodies, due to their accessibility and the frequency of amino acid changes in their proximity (17).

The A/Argentina/V425/98 strain exhibited low reactivity in the $\mathrm{HI}$ test for all the H3N2 sera tested. From a genomic point of view this strain was similar to the rest of the Argentine and Uruguayan strains. This could be due to the fact that point mutations occurring near the receptor binding site located in the HA1 portion of the HA provoke a conformational modification of this molecule. This type of modification would, in the HI test, make the antisera recognize with less affinity this strain in relation to the receptor of the turkey red blood cell. Thus, the information obtained from the antigenic and the genomic studies is complementary, and the analysis of both is needed in order to reach a justifiable conclusion with regards to the definition of new variants.

Our study indicates that the predominant influenza A H3N2 strains circulating in Argentina in 1998 did not behave antigenically in a way similar to the H3N2 component of the vaccine formula recommended for the Southern Hemisphere. Clearly, the greater this kind of difference is, the less effective the vaccine would be.

For many years in Argentina and other countries of the Southern Hemisphere there had been an imbalance between the circulating A H3N2 virus and the corresponding vaccine antigen, with a delay of up to two annual periods (7). To deal with that concern, since 1998 the WHO has held its second annual meeting each September to consider the information gathered in the Southern Hemisphere and decide if there is a need to reformulate the vaccine to be used by these countries. During 1998 the majority of the viruses reported by the other Southern Cone countries had antigenic characteristics similar to those of the viruses isolated in Argentina. In 1999 and 2000 a better correlation between the vaccine and the circulating strains was observed, following the WHO move to begin recommending a formula specifically for the Southern Hemisphere (unpublished data).

Before we developed this technology in Argentina, information about the influenza season in the country was of poor quality and was slow in arriving. Since our initial study the quality and quantity of information generated in Argentina has improved.

This type of work should be encouraged for the other national influenza reference centers. In this way countries will have the information that is needed to help choose the most appropriate vaccine components each year and thus provide their citizens with the best possible protection against influenza.

Acknowledgments. We thank Adrián Lewis of the Servicio de Cultivo de Tejidos at the INEI-ANLIS "Carlos G. Malbrán" for preparing the MDCK cells for us, and Gustavo Palacios of the Servicio de Neurovirosis at INEIANLIS “Carlos G. Malbrán” for helping us with the phylogenetic trees.

\section{REFERENCES}

1. Cox N, Subbarao K. Influenza. Lancet 1999; 354(9186):1277-1282.

2. Tillett HE, Smith JW, Clifford RE. Excess morbidity and mortality associated with influenza in England and Wales. Lancet 1980;1(8172): 793-795.

3. Webster RG, Laver WG. Antigenic variation of viruses. In: Kilbourne EK, ed. Influenza viruses and influenza. New York: Academic Press; 1975. p. 270-315.

4. Laver WG, Gerhard W, Webster RG, Frankel ME, Air GM. Antigenic drift in type A influenza virus: peptide mapping and antigenic analysis of A/PR/8/34 (H1N1) variants selected with monoclonal antibodies. Proc Natl Acad Sci 1979;76:1425-1429.

5. Lindstrom SE, Hiromoto $Y$, Nerome R, Omoe K, Sugita S, Yamazaki Y, et al. Phylogenetic analysis of the entire genome of influenza $\mathrm{A}$ (H3N2) viruses from Japan: evidence for genetic reassortment of the six internal genes. J Virol 1998;72(10):8021-8031.

6. Hampson AW, Cox NJ. Global surveillance for pandemic influenza: are we prepared? In: Brown LE, Hampson AW, Webster RG, eds. Options for the control of influenza III. Amsterdam: Elsevier; 1996. p. 50-59.

7. Savy V, Baumeister E, Pontoriero A. Estudio antigénico de cepas de influenza A (H3N2) circulantes en la Argentina y su relación con las cepas vacunales. Medicina (B Aires) 1999. 59(3):225-230.

8. Recommended composition of influenza virus vaccines for use in the 1997-1998 season. Wkly Epidemiol Rec 1997;72(9):57-61.

9. Kendal AP, Pereira MS, Skehel JJ. Viral isolation. In: Kendal A, Pereira M, Skehel J, eds. Concepts and procedures for laboratorybased influenza surveillance. Atlanta, Georgia, United States: Centers for Disease Control and Prevention and Pan American Health Organization; 1982. p. B7-B16.

10. Kendal AP, Pereira MS, Skehel JJ. Hemagglutination inhibition. In: Kendal A, Pereira M, Skehel J, eds. Concepts and procedures for laboratory-based influenza surveillance. Atlanta, Georgia, United States: Centers for Disease Control and Prevention and Pan American Health Organization; 1982. p. B17-B35.

11. Genetics Computer Group. Program manual for the GCG package, version 8.0 (1994). Madison, Wisconsin, United States: Genetics Computer Group; 1996.

12. Felsenstein J. 1993. PHYLIP phylogeny inference package, version 3.57. Seattle, Washington, United States: University of Washington; 1993
13. Page RDM. TREEVIEW: an application to display phylogenetic trees on personal computers. Comput Appl Biosci 1996;12(4):357-358.

14. Saitou N, Imanishi T. Relative efficiencies of Fitch-Margolish maximum-parsimony, maximum-likelihood, minimum-evolution and neighbor-joining methods of phylogenetic tree construction in obtaining the correct tree. Mol Biol Evol 1989;6:514-525.

15. Wiley DC, Skehel JJ. The structure and function of the hemagglutinin membrane glycoprotein of influenza virus. Ann Rev Biochem 1987;56:2887-2896.

16. Hay A, Lin Y, Cameron K, Gregory V. Annual report, WHO Influenza Centre, London. August 1997-July 1998. London: WIC; 1998.

17. Colman PM, Varghese JN, Laver WG. Structure of the catalytic and antigenic sites in influenza virus neuraminidase. Nature 1983; 303(5912):41-44.

Manuscript received 21 November 2000. Revised version accepted 23 February 2001. 
RESUMEN Objetivos. Debido a la ausencia de correlación entre el componente A H3N2 de la vacuna antigripal recomendada para el período de 1994 a 1997 y los virus entonces circulantes en Argentina, se decidió estudiar las relaciones antigénicas y genómicas entre las cepas A H3N2 circulantes en Argentina en 1998 y el correspondiente componente de la vacuna recomendada para ese año por la Organización Mundial de la Salud.

Métodos. Se seleccionaron 18 cepas de virus influenza A H3N2 aisladas en Argentina en 1998 y se efectuó un estudio antigénico y genómico de sus proteínas hemaglutinina (HA) y neuraminidasa (NA). En el estudio genómico también se investigaron 3 aislados procedentes de Uruguay. Las cepas argentinas y uruguayas se compararon con las cepas de referencia.

Resultados. Se comprobó que las 18 cepas argentinas eran similares a la cepa A/ Sydney/5/97 (H3N2), y no a la cepa A/Wuhan/359/95 (H3N2), componente de la vacuna. El estudio genómico confirmó este resultado.

Conclusiones. El método aplicado en este estudio ha mejorado cuantitativa y cualitativamente la información acerca de la influenza en Argentina. Se deberían alentar estudios de este tipo en otros países, con el fin de contribuir a la elección de los componentes más adecuados para la vacuna de cada año y proporcionar a los vacunados la mejor protección posible frente a la influenza.

\title{
Gorgas Memorial Institute Research Award
}

Deadline to apply: 1 August 2001

The Gorgas Memorial Institute is accepting applications from Ph.D.- or M.D.-level re searchers from Central America, South America, or the Caribbean to conduct short-term collaborative biomedical research projects focusing on tropical diseases and on learning new techniques and approaches applicable to the study of such diseases. Applicants should hold a position at a research, medical, public health, or teaching institution in their country and should have the endorsement of their home institution to participate.

Awards will generally have a maximum value of US\$25000, to cover the costs of roundtrip travel, housing, and supplies required for a project. The number of awards made will depend on the availability of funds, but there will normally be at least two awards each year.

The deadline to apply is 1 August 2001. Among the supporting materials that the application must include are: 1) a proposal describing the research goals of the project, the methods or plan of action, and the relevance to health problems; 2) the applicant's curriculum vitae and copies of several recent publications; 3) a letter from the applicant's home institution endorsing the project; and 4) a letter from the collaborating investigator at the host institution indicating his or her willingness to participate in the project.

\author{
Inquiries and applications should be addressed to: \\ Gorgas Memorial Institute Research Award \\ American Society of Tropical Medicine and Hygiene \\ 60 Revere Drive, Suite 500 \\ Northbrook, Illinois 60062 \\ United States of America \\ http://uww.astmh.org/funding/gorgas.html
}

